\title{
Natural disasters: an engineer's perspective in Nepal
}

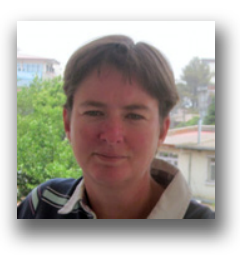

Kirsteen Merrilees BEng, MSC, CEng, MICE, CMgr, MCMI

Principal Consultant, IMC Worldwide Ltd, Redhill, UK

In 2011 an earthquake measuring 6.9 on the Richter scale occurred on the border of Nepal and Sikkim. This sparked a flurry of interest in improving Nepal's resilience to disasters. In April 2015, numerous large earthquakes were experienced throughout central Nepal. The impact of earthquakes in Nepal is exacerbated by poor quality structures, poor public infrastructure, extreme poverty and a lack of access to the worst affected areas, making the country extremely vulnerable to earthquakes and a range of other natural disasters including landslides, flooding, fires - all of which kill hundreds of people each year. The role of engineers in helping governments and local communities prepare for, mitigate and recover from these disasters is a critical aspect of the national strategy for disaster risk management. Significant progress is being made in raising the profile of resilience and the role of engineers. The efforts of the engineering community in the immediate aftermath of the 2015 earthquake resulted in unprecedented positive messages in the Nepal media on the role of engineers. With initiatives in motion to improve engineering practice, the time is ripe for the Nepali engineering community to influence government and the construction sector to improve the country's resilience to natural disasters.

\section{Introduction}

On 18 September 2011, an earthquake of magnitude (M) 6.9 occurred under the Himalayas, with its epicentre located on the border of Nepal and Sikkim. This sparked a flurry of interest in improving Nepal's resilience to such disasters which forms the basis of this paper.

More recently, Nepal has experienced numerous earthquakes: an M7.8 on 25 April 2015 followed within hours by M6.6 and M6. 1 aftershocks, M6.7 on the 26th of April and M7.3 on 12th May. As of 18 June 2015, there have been 324 aftershocks of M4.0+, with several of these occurring daily (NSC, 2015). This paper has been updated to include some experiences from the early recovery phase of these latest earthquakes.

The impact of earthquakes in Nepal is exacerbated by poorquality structures, poor public infrastructure, extreme poverty and lack of access to the worst affected areas. Relief efforts are hindered by poor weather conditions, and secondary impacts such as large landslips and debris flows which cause further destruction.

In 2011, the official death toll in Nepal was only seven; with three of these being in the Kathmandu Valley some $270 \mathrm{~km}$ away from the epicentre (Figure 1). Hundreds of people suffered injuries, mostly by people panicking and jumping from upper storeys, with only 74 deaths recorded as directly associated with the earthquake. In all, 7827 buildings were destroyed displacing 47000 people, another 13268 buildings were damaged (IFRC, 2012a) along with hundreds of schools and public buildings. Several recovery programmes were established to reinstate schools and public buildings, but many families were still living in temporary shelters more than a year later. The engineering community played a significant role in this recovery effort, but was involved only in the technical aspects of recovery programmes rather than contributing to the development of longer-term resilience initiatives. A lack of awareness of resilience among the construction sector has increased vulnerability to disasters in some cases.

\section{Nepal's vulnerability to natural disasters}

Nepal sits between India and China along the Himalayan mountain range formed by the colliding Indian and Tibetan tectonic plates. Nepal rises from 60 to $8848 \mathrm{~m}$ above sea level at the top of Mount Everest. The Himalayas are still rising, creating an active seismic zone. According to the National Society of Earthquake Technology (NSET), 92 active faults have been identified in Nepal. In 2012 alone, more than 30 earthquakes were recorded ranging from 4.0 to 5.7 on the Richter scale. In the twentieth century, it is estimated that more than 10000 people lost their lives due to four major earthquakes - the greatest cause of unnatural deaths during that period (NSET, 2015). 


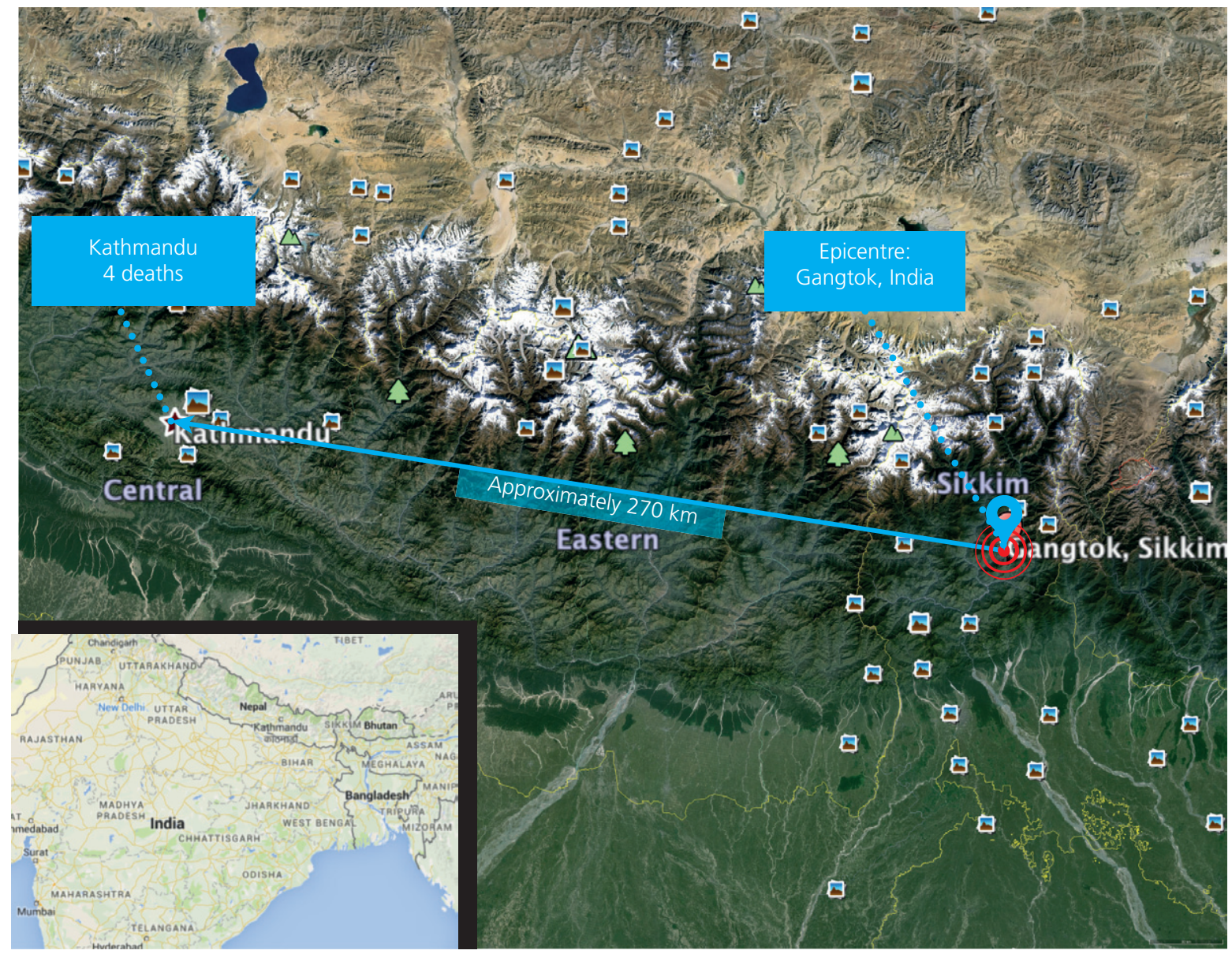

Figure 1. Location map of Nepal and the September 2011

earthquake

The World Bank classifies Nepal as a global disaster 'hotspot' (World Bank, 2005), with an average of 670 disasters recorded each year and 1551 individual disaster events being recorded in 2010 alone. Several individual disaster events during 2012 had direct death tolls in hundreds. Disaster data show that epidemics, floods, landslides, thunderstorms and earthquakes have been responsible for the highest numbers of deaths and injuries over the last 40 years (MOHA, 2011).

Nepal's vulnerability to this wide range of natural disasters is compounded by its harsh topography and extreme poverty. The country's steep and fragile slopes, long dry seasons and high-intensity monsoon rains contribute to the high prevalence of landslides, floods, droughts, storms and lightning strikes, wild fires, glacial lake outbursts, avalanches, epidemics, and extreme heat and cold. Anticipated climate change impacts are likely to result in a worsening of all weather extremes, erosion and slope fragility, further increasing the likelihood and impact of future disaster events (Practical Action, 2010). Furthermore, as one of the poorest countries in the world, ranking 157th out of 187 countries (UNDP, 2012) its population has little resilience to the shocks outlined above.

Poor physical access to much of the rural population and the resultant poor-quality health services have contributed to outbreaks of epidemics, which is the leading cause of disasterrelated deaths (53\%) and injuries $(75 \%)$. Landslides and floods are often interconnected and together contribute to $27 \%$ of disaster-related deaths, directly affecting almost $15 \%$ of the total population. Earthquakes contributed to just $12 \%$ of disaster-related injuries during this period.

Nepal also suffers from weak governance which makes it vulnerable to man-made hazards including collapsing buildings, traffic accidents, construction-induced landslides (not distinguished in the above statistics), deforestation and erosion, conflict and violence. The actions of humans, and in particular of the construction and transport sectors, significantly contribute 


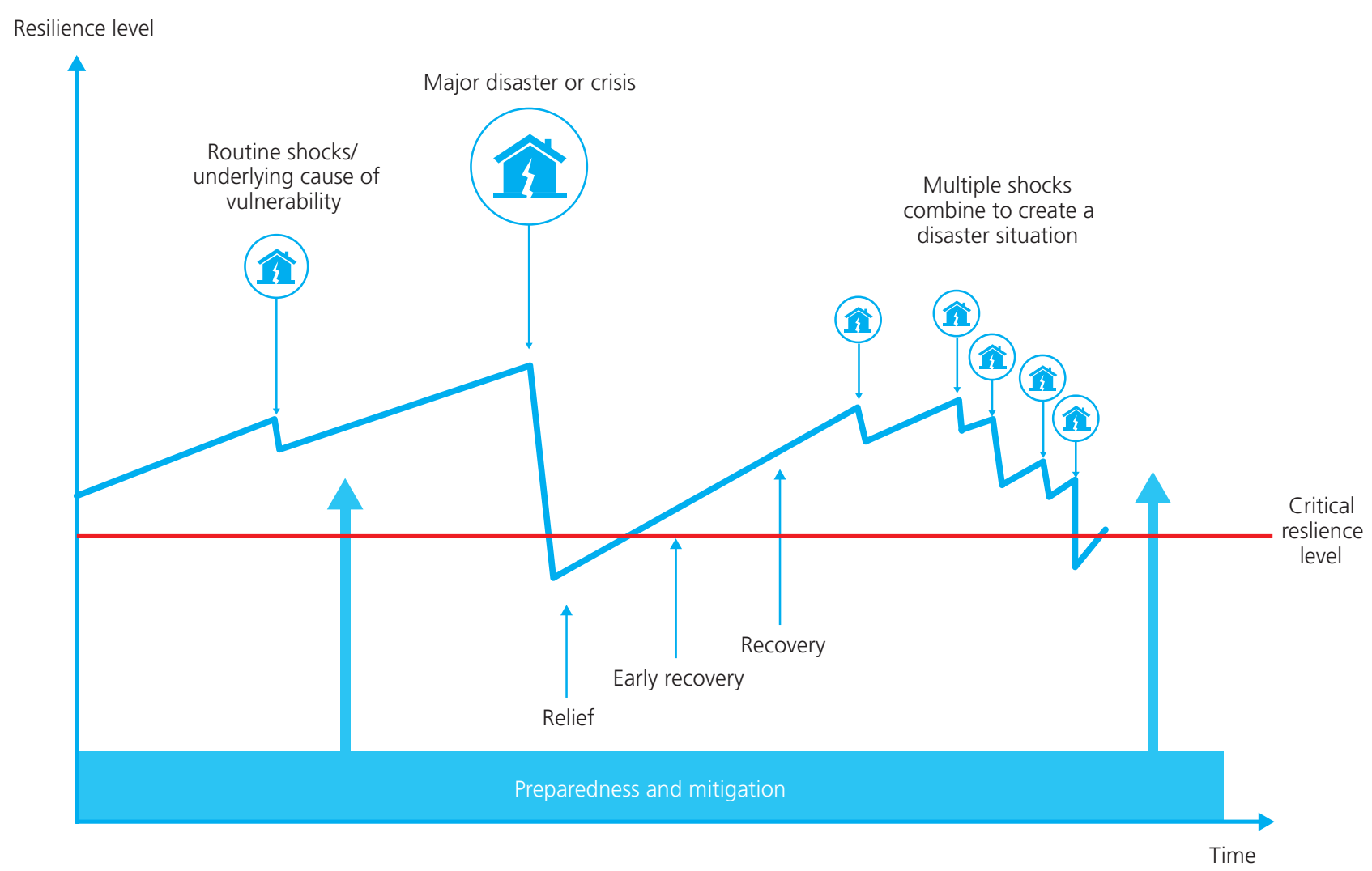

Figure 2. Illustration of the effects of interventions to strengthen resilience over time

to both man-made and natural hazards through poor planning and bad construction practices. Many roads, for example, are constructed with no drainage or retaining structures causing landslips which result in deaths and injuries and cut-off communities from essential social and economic services. Quarrying, deforestation, overgrazing and unsustainable resource use further destabilises fragile slopes and ecological systems.

\section{Developing resilience}

In Nepal, the National Risk Reduction Consortium (NRRC, 2013) has been working to develop an agreed definition of disaster resilience, which includes the ability to

- anticipate, minimise and absorb potential stresses or destructive forces through adaptation or resilience

- manage or maintain certain basic functions and structures during disaster events

recover or 'bounce back' after an event.

They have gone further to develop nine minimum characteristics of a disaster-resilient community, which focus on disaster-related organisational structures, information management, and risk management planning and resourcing.

Figure 2 illustrates the effects of interventions to strengthen resilience over time and is derived from a model developed by the International Federation of Red Cross and Red Crescent Societies (IFRC, 2012b). It demonstrates how preparedness and mitigation as part of general and longer-term development interventions gradually improve a community's resilience, but that routine shocks often counter these interventions. Routine shocks are related to the underlying cause of vulnerability of a community and can include, for example, environmental degradation, food insecurity, poor access, political instability and weak governance, ill health - the usual range of issues that affect overall development. In general, a community can continue to develop and be considered resilient only as long as development interventions include sufficient preparedness and mitigation to continue to overcome these shocks.

The situation changes when a major disaster occurs and a community is unable to cope or 'bounce back' without external support - that is they fall below a 'critical' resilience level. 
Such disasters include high-magnitude earthquakes or extreme weather conditions as well as larger-scale routine shocks that have greater than normal impact or frequency, preventing recovery between events. A disaster or crisis can be caused by anything that pushes people to their resilience limit and puts lives at risk and there is a need for outside help in the form of relief and recovery interventions.

Relief interventions are short-term, post-disaster humanitarian responses to provide basic food, drinking water, medication and shelter to affected communities. Early recovery includes establishing more robust temporary facilities to replace those lost, for example, prefabricated portable structures from which health and administrative services can be reinstated. Full recovery is the permanent replacement of lost infrastructure and facilities, applying 'build back better' principles where possible.

Resilience is also about putting in place measures that allow a community to adapt to and prepare for anticipated events to prevent falling below their critical resilience limit. Developing resilience therefore requires an assessment of vulnerability and the development of appropriate mitigation or preparedness interventions. It is similar in approach to that of standard risk management processes as applied in the engineering industry. Potential disaster events (risks) are identified, their anticipated likelihood/frequency and impact are assessed and appropriate mitigation or preparedness interventions (risk treatment options) are identified and implemented. The analysis and interventions are commonly referred to as disaster risk reduction or disaster management strategies or plans.

As with standard risk management, disaster management decision making includes some form of cost-benefit analysis and takes into account the predictability of disaster events. Vulnerable communities need to weigh up the cost of resources and effort of mitigation or preparedness interventions against the likelihood or anticipated impact of a certain type of disaster event taking place. Disaster events that can be predicted relatively easily (occur often in known locations) are more likely to be managed well than those that are difficult to predict (occur rarely or at random locations). For example, mitigation and preparedness measures for flood events that happen in specific locations every monsoon season are far better managed and resourced than those for earthquakes or storms, which can occur anywhere at any time.

Typical barriers for improving disaster resilience in Nepal are as follows.

- Extreme poverty and food insecurity: Poor people's critical resilience levels can be so low that they are barely resilient to everyday events let alone significant shocks.

- Poor access: Access to many communities requires several days walking. This hinders support for resilience and significantly increases per-capita intervention costs.

- Uncertainty: Many disasters cannot be predicted and people tend to think 'it won't happen to us' or 'why should I protect against something that might never happen?'.

- Lack of knowledge of appropriate interventions: Lack of awareness of the causes or measures that can reduce vulnerability create a sense of helplessness.

- Traditional practices and belief systems: Communities that believe disasters are caused by gods or spirits may actively prevent practical measures to reduce vulnerability, preferring to trust in religious ceremony.

- Lack of institutional coordination and resources: Implementation of the government's resilience plans is hindered by inadequate resources and ineffective institutional arrangements.

\section{Engineering responses}

There is great potential for engineers to contribute significantly to resilience by using their technical expertise, their management skills and their practical understanding of the physical world to support resilience through appropriate engineering responses for disaster preparedness, mitigation and recovery.

\subsection{Preparedness}

Preparedness includes the development of disaster risk reduction or management strategies and plans and implementation of pre-disaster measures. From an engineering perspective, typical preparedness activities might include advance planning for maintaining access to emergency services and putting in place the necessary infrastructure for managing anticipated emergencies.

Kathmandu Valley is the most vulnerable city in the world to an earthquake in terms of life loss. High-magnitude earthquakes are a certainty but no one can predict when they may happen again. Predictions made in 2001 suggested that a high-magnitude earthquake would destroy most of the city, killing about 70000 people ( $4.5 \%$ of the city's population) and injuring many more (GHI, 2001) and that the city will be cut-off from outside help for weeks. In 2015 Nepal was lucky - it was only an M7.8 earthquake and not the 'big' one Nepal had been anticipating. The direct impact is estimated at 8700 deaths, 280000 houses damaged and 500000 houses destroyed across the country, with an estimated 2.8 million people in need of humanitarian assistance (UNOCHA, 2015). Most of the deaths and damage are in rural areas and not in Kathmandu itself.

Preparedness plans in Kathmandu had included

- identifying appropriate evacuation centres for displaced persons and providing these with storage units for emergency supplies 
- procuring appropriate emergency supplies including search and rescue equipment, temporary shelters, portable toilets, water treatment systems, medical and food supplies

- developing mechanisms for mobilising heavy equipment to reopen key access routes to facilitate relief and early recovery efforts

developing plans and procuring key temporary and portable infrastructure.

At least some, if not all, of these plans proved effective in managing the immediate aftermath of the 2015 earthquakes.

\subsection{Mitigation}

Mitigation measures are about trying to reduce the risk of potential disasters. From an engineering perspective, this includes the development and application of resilient design standards and codes, retrofitting measures and early warning systems.

The UK and Nepali governments, through the Rural Access Programme (RAP), are supporting the inclusion of resilience and climate change adaptation in a range of rural infrastructure design standards, such as roads and trails, irrigation, renewable energy technologies and market-related infrastructure (e.g. buildings for processing and storage). New resilient road bridge designs have recently been introduced including

- the use of large single span to reduce the need to construct vulnerable and environmentally intrusive intermediate support piers in the main river channels

- increased freeboard to the deck soffit to deal with the risk of high water levels due to adverse weather, watercourse blockages or sudden breaches from upstream avalanches and glacial lake outbursts

- simpler and more reliable bearing details together with dedicated earthquake lateral restraints to deal with movements and loading caused by earthquake events

- use of innovative bridge construction techniques such as balanced cantilever launching methods to enable large spans to be erected without the need for construction of temporary supports in fast flowing rivers.

While these bridges may not seem unusual or innovative in the developed world, they are considered state of the art in Nepal and many Nepali engineers had to 'see it to believe it'. Both bridges built under RAP according to these new standards were undamaged by the 2015 earthquakes.

For buildings, Nepal has developed a building code that provides resilience guidelines for a range of typical building types, but so far implemented only in a handful of municipalities.

Several donor-supported programmes have been retrofitting major hospitals and schools. The 2011 earthquake recovery programme included repair and retrofitting of selected schools that had suffered minor damage to reduce their future vulnerability.

The retrofitting programme was particularly difficult to introduce in rural areas as most of the damaged structures were nonengineered mud-mortar masonry and their basic designs and layouts increased vulnerability to earthquakes. The government of Nepal has been working to develop retrofitting solutions for a range of traditional construction methods, building styles and layouts, but has focused to date on those common to the Kathmandu Valley and urban areas. While this is sensible in terms of protecting the larger and denser population centres, $\sim 83 \%$ of Nepalis live in rural areas (CBS, 2012) and in houses built using traditional construction styles and methods. Although the basic principles for retrofitting are the same, development of appropriate and cost-effective solutions require structural analysis and a return to core engineering principles - not something ordinary rural communities have access to.

Sometimes mitigation measures are not appropriate. For example, the natural slopes of the Himalayas and its foot hills are geologically new and extremely fragile. Rockfalls and landslips are a common occurrence throughout the hill and mountain areas of the country and there are many 'live landslips' where the slope surface and its underlying material are so fragile that there is almost continuous slope movement.

Road construction costs are already relatively high in Nepal due to the topography and limited access to good-quality natural resources. A journey of just $30 \mathrm{~km}$ as the crow flies can require a road length of $90 \mathrm{~km}$ with all the hairpin bends needed to traverse hillsides between valleys and passes which can have height gains of $1000 \mathrm{~m}$ or more on very steep slopes (Figure 3). On low

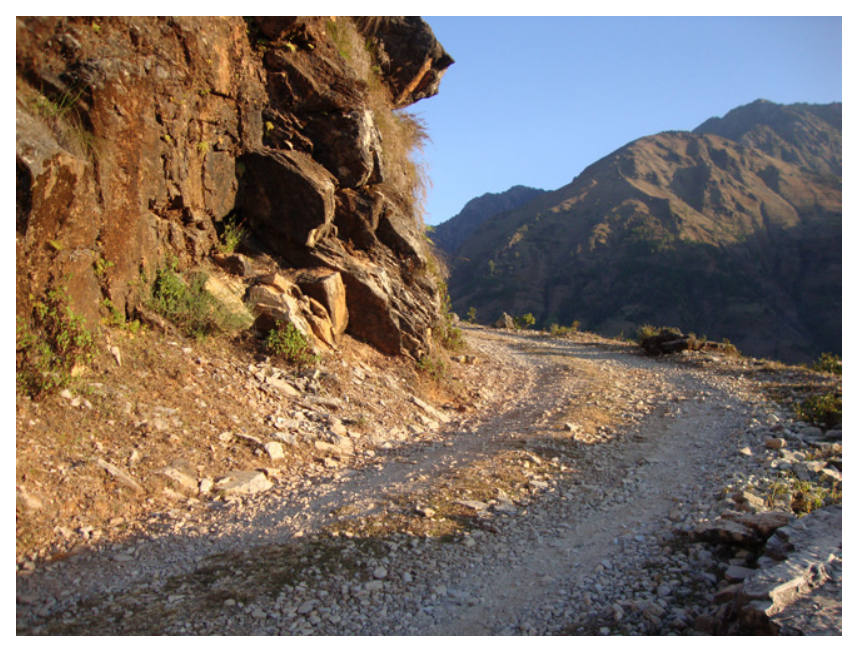

Figure 3. Photograph of a typical road in a hill area of Nepal 
trafficked rural roads, justified in terms of social benefits rather than economic rates of return, retaining walls and bioengineering can be used to stabilise small or shallow landslips, but not against very large or live landslips. In these cases, it is more effective and reliable to develop community-led early warning systems so that a road can be closed to traffic when rainfall parameters reach a predefined risk level.

\subsection{Recovery}

The recovery phase is where the role of engineers is most widely publicised. During early recovery, engineers are responsible for reopening key access routes and providing temporary infrastructure. For longer-term recovery, they are responsible for the repair or reconstruction of damaged public infrastructure and housing. Engineers make excellent managers for relief and recovery efforts due to their strong project and logistics management skills.

Following the 25 April 2015 M7·8 earthquake, the engineering community mobilised immediately to carry out rapid visual damage assessments to advise people whether their homes were safe to return to. In all, 700 members of the Nepal Engineering Association volunteered the day after the first earthquake, by the end of the month 3500 engineers had volunteered and assessed more than 60000 buildings in Kathmandu and other urban centres.

In rural areas, the earthquake caused numerous landslides and rockfalls which blocked roads and hindered relief distribution efforts. Teams of engineers mobilised to procure heavy earth moving equipment and clear these blockages. The RAP cleared $97 \mathrm{~km}$ in Sindhupalchok district in $6 \mathrm{~d}$, then again after the 12th May earthquake. The slopes are now extremely fragile and teams are on standby to attempt to keep the roads open during the monsoon to ensure local people can continue to receive relief materials.

In terms of improving resilience, the 'build back better' approach ensures that replacement structures are resilient. Often, it is only in the aftermath of a disaster that there is sufficient public and political support to accept the higher cost of improved design and construction standards that incorporate disaster resilience. Engineers involved in the recovery phase should make the most of this opportunity and exert their influence to promote resilient standards that can be applied to all new construction in the future - strengthening mitigation measures to reduce future recovery costs. In eastern Nepal after 2011, all recovered school blocks followed the 'build back better' approach, following latest Ministry of Education design standards. In some cases, these designs were further enhanced to provide a better learning environment for children, including features to improve temperature and noise control and to increase the level of natural light in the classrooms (Figure 4).

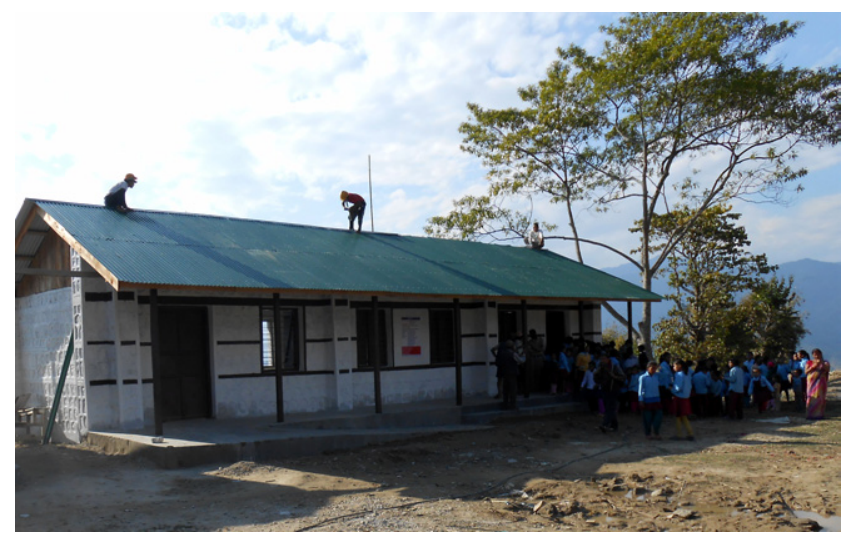

Figure 4. Photographs of a recovered school block demonstrating build back better approach

In developing countries, the recovery effort is often funded almost entirely through international multilateral and bilateral donor agencies. These agencies tend to be more open to, and often insist on, the build back better approach. However, constraints in terms of locally available materials, technical expertise and capacity of local builders and masons also need to be taken into account. The recovery efforts after the 11th September earthquake in Nepal specifically incorporated traditional construction techniques and capacity building of local masons to ensure that they could be constructed locally. Many had never even worked with reinforced concrete so what seemed the simplest of resilient structures required intensive training. This also supported the mitigation phase, providing a trained pool of local resilience expertise that could ensure new structures included key resilience features (Figure 5).

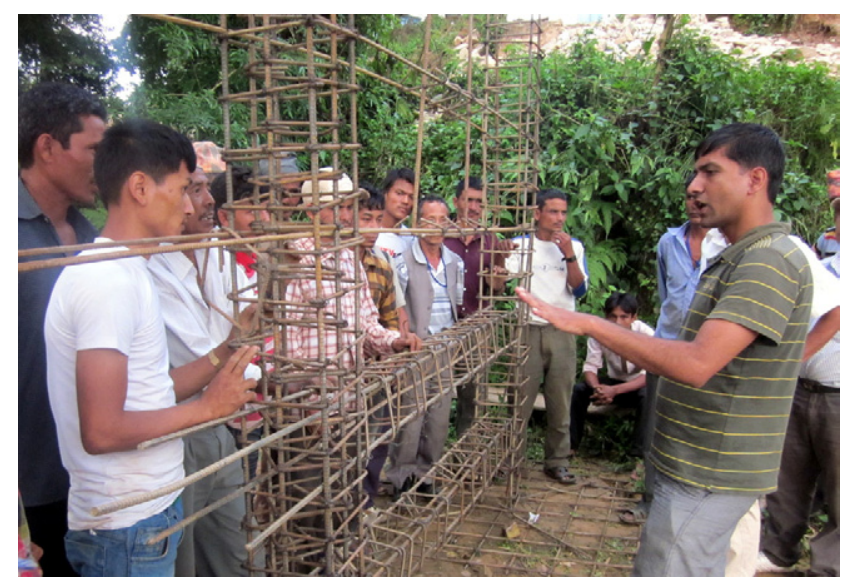

Figure 5. Photograph of masons undergoing training in resilience techniques 
In response to the 2015 earthquake, the Global Shelter Cluster is working with the government of Nepal and technical organisations to develop a range of appropriate reconstruction and retrofitting solutions that can be applied by local masons and engineering technicians with the minimum of training. This will incorporate 'build back better' principles where appropriate.

\section{Wider 'non-technical' involvement}

There are a number of 'non-technical' ways in which engineers can contribute to developing resilience.

\subsection{Improving resilience knowledge uptake}

Nepal has too few qualified and experienced engineers to cope with all the work required and in rural areas people have to be self-reliant. Construction work is carried out by local builders and masons with little formal education or vocational training. Most have learned techniques passed down through older generations by working with others. As a result, most buildings in rural Nepal are non-engineered.

The lack of resilient engineering capacity is partly linked to the general out-migration of educated or skilled Nepalis, but is exacerbated because disaster resilience is not part of their technical education. Despite the country's high vulnerability and disaster statistics, earthquake engineering and the national building codes are an 'optional' course in the university curricula. A structural engineer can qualify without ever having studied or understood the codes. There are no courses for engineers below master's level on disaster risk management.

There is an on-going debate in the engineering community over developing resilient structures in rural areas. Some feel that building designs and retrofitting works must fully comply with engineering codes to meet the defined resilience criteria, with detailed designs for each structure to ensure optimal value for money solutions - the 'no compromise' camp.

While this makes sense for providing safe structures in a costeffective way, it restricts development of resilience to locations where adequate engineering services are available. There is a growing movement to develop a more accessible means of improving structural resilience throughout the country, enabling more people to benefit from improved resilience, using simplified model solutions, non-technical handbooks and technical training for masons and builders - the 'something is better than nothing' camp.

Engineers can help by researching and developing simple and low technology solutions, using locally available materials and skills where possible. These can be presented in simple handbooks using diagrams and pictures rather than text and formulas. These can explain the key resilience features and techniques and highlight common mistakes or features that increase vulnerability. The engineering community has a responsibility to train local technicians, builders and masons in how to use these handbooks and master the techniques in them. Several of the masons trained in eastern Nepal after the 2011 earthquake said that they wished they had known these things before. Some had recently built structures that they now knew to be unsafe. Within months of receiving the training, many had incorporated their resilience knowledge in new structures.

Such handbooks have proven effective in improving understanding of technical issues in community-managed infrastructure, so it seems appropriate to extend this approach to community-managed resilience.

\subsection{Embedding resilience in infrastructure projects}

Many donors now require disaster risk reduction and resilience to be embedded in their infrastructure and development programmes. All infrastructure designs and construction techniques must take into account disaster vulnerability and resilience. Standard environmental and social impact assessments do not specifically consider disaster vulnerability or resilience and there is growing recognition that it would be appropriate for them to do so. There is a suggestion that a specific disaster impact assessment should be introduced for projects, looking at disaster impact from two perspectives.

How does the proposed intervention affect vulnerability of the affected area?

- How might anticipated hazards affect the intervention?

To answer either of these questions, first it requires that the disaster vulnerability of the project area is assessed. The most common tool for this is vulnerability mapping, involving analysis of historical disaster events or data collected through scientific surveys, to identify safe and vulnerable areas. It includes identification and vulnerability assessment of potential secondary impacts that may occur in the short, medium or long term after the initial disaster. For example, an earthquake in Nepal in 1988 caused a number of relatively small landslides which combined to silt up a major river. Some years later, intense rainfall combined with the reduced capacity of the river resulted in massive flooding.

Vulnerability mapping is an essential step in selecting sites for interventions, but is often ignored. Participatory vulnerability assessments are powerful tools in promoting good governance in infrastructure planning and ensuring that infrastructure and 
services are located in safe places, rather than at the whim of local elites and politicians.

Where an intervention may increase vulnerability, appropriate mitigation measures can be developed. In some cases, this may simply be to develop some form of early warning systems.

In Nepal, early warning systems for flooding of major rivers is well established and played a key role in saving hundreds of lives during the floods in western Nepal in June and July of 2013 (Practical Action, 2013). Efforts are now moving towards improving early warning systems for upstream flooding, landslips and debris flows, and for agricultural shocks (extreme weather events, pests and disease).

\section{Emerging perceptions - the engineering 'gap' and how it can be closed}

Despite all the difficulties that Nepal faces in terms of high disaster vulnerability, poor governance and lack of funds, the government of Nepal and a range of key actors are making significant progress in raising the profile of disaster resilience across the country. The NRRC brings together a range of central level organisations representing policy makers and practitioners to promote and coordinate disaster risk reduction efforts. These have included disaster-related legislation and implementation strategies, emergency operation centres, and disaster risk management guidelines for national to community levels. It has supported the relevant government departments to develop resilient design standards, building codes and guidelines for new construction and retrofitting. It has coordinated efforts to develop early warning systems and effective response mechanisms for floods.

Central level politics means that the key disaster management legislation has stalled. Institutional capacity, financial and human resources at all levels are insufficient to implement the strategy. The building certification process is flawed - the certificate is given based on the design, not the actual construction. Planning processes are inadequate to address specific locational risks. The disaster risk reduction mechanisms that have been introduced reach only a handful of communities.

Previously, very few engineers have been involved in disaster risk reduction efforts outside of the building codes. The government staff responsible for managing roads and rural infrastructure is not involved in the NRRC or the disaster risk reduction initiatives it has supported. Inadequate control of infrastructure development and the lack of appreciation of disaster risk and vulnerability among the engineering community mean they have, directly or indirectly, been responsible for increasing disaster vulnerability in places and for constructing facilities in vulnerable places. There is a great need for further engineering research into cost-effective, low-technology solutions for resilient buildings, infrastructure and water and slope management systems that can be managed by local communities.

Engineers currently require no postgraduate training or professional experience to practice as fully qualified engineers in Nepal. Since February 2015, the National Engineering Association and Nepal Engineering Council have been working together, with support from the RAP, to develop a system for a professional qualification with associated continual professional development and graduate development programmes, broadly based on the Institution of Civil Engineers' model. This may take some time to come into effect, but it should ensure in time that all practicing engineers in Nepal have a minimum level of practical experience, have a better sense of professionalism and responsibility towards society, and an understanding of safeguards management including disaster risk reduction and resilience.

As a result of the efforts of the engineering community in the immediate aftermath of the 2015 earthquake, for the first time ever in Nepal the media and society have a positive image on the role of engineers. With initiatives already in motion to improve engineering practice, the time is ripe for the Nepali engineering community to improve the image of the engineering profession and to play their part to influence government, clients and the construction sector to improve the country's resilience to natural disasters.

It is an exciting time to be an engineer working in Nepal.

\section{Acknowledgements}

The author acknowledges the team that delivered the Earthquake Recovery and Disaster Risk Reduction in Eastern Nepal project, from which she gained her insights into the role of engineers in disaster resilience, in particular the Deputy Team Leader Mr Gagan Raj Rai, to NSET for their excellent training and technical support, to the NRRC and DFID for their support to the project, and to the Asia Pacific branch of the ICE for inviting the author to present at their conference on natural disasters in January 2012, from which this paper has been developed. She also acknowledges the Nepal Engineers Association and Nepal Engineers Council and their recent efforts in advancing the engineering sector in Nepal.

\section{REFERENCES}

CBS (Central Bureau of Statistics) (2012) National Planning and Housing Census 2011. Central Bureau of Statistics

National Planning Commission Secretariat, Government of Nepal, Kathmandu, Nepal.

GHI/UNHCR (GeoHazards International and United Nations

Centre for Regional Development) (2001) Global

Earthquake Safety Initiative (GESI) Pilot Project.

GHI/UNHCR, Final Report, Palo Alto, CA, USA. 
IFRC (International Federation of Red Cross and Red Crescent Societies) (2012a) Disaster Relief Emergency Fund (DREF) Nepal: Earthquake Update No. 4, 10 February 2012. IFRC, Geneva, Switzerland.

IFRC (2012b) The Road to Resilience: Bridging Relief and Development for a More Sustainable Future. IFRC, Geneva, Switzerland.

MOHA (Ministry of Home Affairs) (2011) Nepal Disaster Report. MOHA, Kathmandu, Nepal.

NRRC (National Risk Reduction Consortium) (2013) Flagship 4 Handbook: Nepal's 9 Minimum Characteristics of a Disaster Resilient Community. NRRC, Kathmandu, Nepal.

NSC (National Seismological Centre) (2015) Nepal Website. NSC, Kathmandu, Nepal. http://seismonepal.gov.np/index. php?action $=$ earthquakes\&show $=$ recent $($ accessed 24/08/ 2015).

NSET (National Society for Earthquake Technology) (2015) Hazards in Nepal: Earthquakes. NSET, Lalitpur, Nepal. http://www.nset.org.np/nset2012/index.php/menus/menuid58/submenuid-137 (accessed 24/08/2015).

Practical Action (2010) Promoting Adaptation to Climate

Change in Nepal: a Briefing for Government Advisors and Development Practitioners. PA, Kathmandu, Nepal.

Practical Action (2013) Early Warning System Saves Lives in Monsoon-Hit, Nepal Website. PA, Kathmandu, Nepal. http://practicalaction.org/blog/where-we-work/nepal/earlywarning-system-saves-lives-in-monsoon-hit-nepal/ (accessed 24/08/2015).

UNDP (United Nations Development Programme) (2012)

Human Development Index. UNDP, New York, NY, USA.

UNOCHA (United Nations Office for the Coordination of Humanitarian Assistance) (2015) Nepal: Earthquake 2015 Situation. UNOCHA, Kathmandu, Nepal, Report No. 20 (as of 3 June 2015).

World Bank (2005) Natural Disaster Hotspots: A Global Risk Analysis. WB, Washington, DC, USA.

\section{WHAT DO YOU THINK?}

To discuss this paper, please email up to 500 words to the editor at journals@ice.org.uk. Your contribution will be forwarded to the author(s) for a reply and, if considered appropriate by the editorial panel, will be published as discussion in a future issue of the journal.

Proceedings journals rely entirely on contributions sent in by civil engineering professionals, academics and students. Papers should be 2000-5000 words long (briefing papers should be 1000-2000 words long), with adequate illustrations and references. You can submit your paper online via www.icevirtuallibrary.com/content/journals, where you will also find detailed author guidelines. 